\title{
CUMULATIVE EFFECTS OF PENFLURIDOL, A LONG-ACTING NEUROLEPTIC DRUG, AS ASSAYED BY ITS BEHAVIORAL ACTIONS
}

\author{
Hisashi KURIBARA and Sakutaro TADOKORO \\ Behavior Research Institute, School of Medicine, \\ Gunma University, Maebashi 371, Japan
}

Accepted July 29, 1976

\begin{abstract}
Penfuridol, a long-acting neuroleptic drug, was repeatedly given to rats well trained on the discriminated avoidance schedule (intertrial interval, $25 \mathrm{sec}$; warning duration, $5 \mathrm{sec}$ ), and accumulation of the effects were investigated by observing the behavioral changes. When penfuridol was orally given in a dose of $2-8 \mathrm{mg} / \mathrm{kg}$ once daily for 10 consecutive days, the suppression of avoidance response was progressively enhanced until the $3 \mathrm{rd}-4$ th day. But from the 4th day, the maximum level of suppression was maintained during the later medication. On its withdrawal, the avoidance response was gradually restored, returning to the initial level in 3-4 days. When 8 $\mathrm{mg} / \mathrm{kg}$ was given at 1-2 weeks after the withdrawal, the same suppression was observed as after the single administration of the same dose. The progressive enhancement of suppression in the early half of the modication period evidently indicated the cumulative effect. The degree of suppression during the plateau showed a linear correlation with the dosage, and was estimated to be about 3.5 times as high as in the corresponding single administration.
\end{abstract}

Previously, the authors reported that penfluridol had the property of a neuroleptic drug, and that the oral administration of more than $2 \mathrm{mg} / \mathrm{kg}$ suppressed various operant behavior in fairly good proportion with the dosage (1). Furthermore, they confirmed that the effect, though delayed, persisted for 2.3 days. When such a long-acting drug with delayed metabolism and excretion is repeatedly given, it is important to take into consideration the cumulative effect.

As for the cumulative effect of repeated administration, there are reports and comments by Gaddum (2), Shannon et al (3), Goldstein et al $(4,5)$ and Wells (6). All of these workers used the drug concentrations as indices of the effect, while few have employed the functional changes. In the present work, we examined the cumulative effect of penfluridol by means of the suppressive effect on the discriminated avoidance response in rats.

\section{MATERIALS AND METHODS}

Subjects: Male Wistar adult rats inbred for more than 20 years by brother-sister mating at the Medical School of Gunma Lniversity were maintained on a solid diet MF (Oriental Yeast Co. Tokyo) and tap water. Five animals of the same age with a stable behavioral baseline after adequate training were used repeatedly through the 6-7 months expcriment. As the indices of drug effects, the frequencies of lever-pressing (response rate) and avoidance rate under the conditioned discriminated avoidance schedule (7-9) 
were used.

Training was initiated when the rats were about 70 days of age, and the body weight was about $200 \mathrm{~g}$. One session consisted of $2 \mathrm{hr}$ training a day, and was held every other day. After the training, the animal was returned to the home cage where food and water could be obtained $a b$ libitum.

The Skinner-box was placed in a wooden soundproof chamber, illuminated to a certain intensity, and temperature was maintained at $22 \pm 2{ }^{\circ} \mathrm{C}$. The air was circulated by a ventilator. The behavior-controlling and response-recording apparatus were all installed in another room, and the gross behavior was observed on a TV monitor.

Procedure: A modification of Hoffman's (7) conditioned discriminated avoidance schedule was used. The procedure of training and the establishment of the behavioral baseline under this schedule have bcen documented elsewhere by Tadokoro $(8,9)$, one of the authors and a brief outline is reported herein. After placing a rat in a Skinner-box made of transparent plastic with a capacity of $25(\mathrm{H}) \times 25$ (W) $\times 19$ (D) $\mathrm{cm}, 200 \mathrm{~V}$ and 0.5 $\mathrm{mA} 50 \mathrm{~Hz} \mathrm{AC}$ was delivered for $0.5 \mathrm{sec}$ through a scrambler to the floor grids at $30 \mathrm{sec}$ intervals. Five sec before the electric shock, both visual and auditory stimuli were presented by means of a pilot lamp and clicking sound from a speaker to warn the animal of the imminent shock. The stimuli were immediately stopped by the first response (lever-pressing) during the warning period, and the program was brought back to the start. It was so programmed that all lever-pressings at other times than the warning period were futile. Also the lever-holding was likewise ineffective. The escape response was excluded from this schedule.

Drug: The drug tested was penfluridol, a neuroleptic drug of diphenylbutylpiperidine group, with the formula of 4-(4-chloro- $\alpha, \alpha, \alpha$-trifluoro-m-toryl)-1-[4,4-bis(p-fluoropheny])butyl]-4-piperidinol. This is a white crystalloid powder, only slightly water-soluble, and was given orally as an aqueous suspension in a $1 \%$ sodium carboxymethyl cellulose (CMC). Since more than $2 \mathrm{mg} / \mathrm{kg}$ p.o. was necessary to exert an effect on operant behavior (1), 2, 4, 8 and $16 \mathrm{mg} / \mathrm{kg} \mathrm{p.o.} \mathrm{were} \mathrm{given} \mathrm{in} \mathrm{cases} \mathrm{of} \mathrm{a} \mathrm{single} \mathrm{administration,} \mathrm{and} 2,4$ and $8 \mathrm{mg} / \mathrm{kg}$ p.o. in cases of repeated dosing. In all cases, a single dose of $1 \mathrm{ml} / \mathrm{kg}$ was prepared in such a way as to contain the above mentioned amount.

A single administration of penfluridol was given at intervals of more than one week, after confirming the behavioral baseline on the previous day of the drug experiment. In the control experiment, a $1 \% \mathrm{CMC}$ solution alone was given. Experiments of the repeated administration were performed after those of a single administration. The administration period was 10 days, and the drug was given once daily immediately before the start of observation. The administration sequence of different dosages was designed at random. Control animals were given $\mathrm{CMC}$ alone for 10 days. After the withdrawal of repeated administration, dosing was always suspended more than a week before resumption, at which time a dose of $4-16 \mathrm{mg} / \mathrm{kg}$ was given and the reproducibility of the effect of a single administration was determined. 


\section{RESULTS}

\section{Changes elicited by a single administration of penfuridol}

Fig. 1 represents changes in the response rates (left) and the avoidance rates (right) elicited by a single administration of $2,4,8$ and $16 \mathrm{mg} / \mathrm{kg}$ p.o. of penfluridol. As already reported (1), the manifestation of effect on the avoidance response was not observed for 3-4 hours after the administration. Here the means for each 5 cases at 24 hr are plotted.

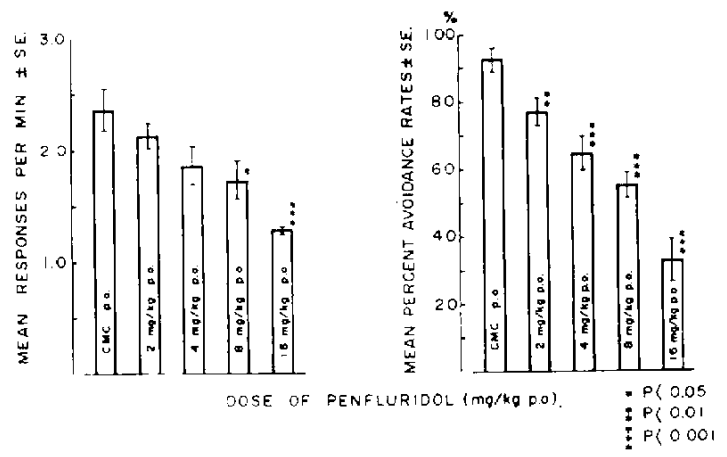

FIG. 1. Effects of single administrations of penfluridol (24 hr after $2-16 \mathrm{mg} / \mathrm{kg} \mathrm{p.o.}$ ) on the conditioned discriminated avoidance response. Left: Response rates. Right: Avoidance rates. * Significantly different from the value in the CMC administered control $(\mathrm{p}<0.05) . \quad{ }^{* *} \mathrm{p}<0.01 . \quad{ }^{* * *} \mathrm{p}<0.001 . \quad$ Vertical lines indicate standard error.

Both the response and avoidance rates were lowered in proportion with the dose of penfluridol. According to the observation of gross behavior, the animals were depressed, and often received electric shocks. At this moment, the animal sprang up with a squeak or tumbled down. The response rates were suppressed significantly at the $5 \%$ level ( $t$-test) as compared with the control value, when the dose was above $8 \mathrm{mg} / \mathrm{kg}$. The avoidance rates were also decreased significantly in doses above $2 \mathrm{mg} / \mathrm{kg}$ p.o. $(\mathrm{p}<0.01)$.

\section{Changes elicited by repeated administration}

$2 \mathrm{mg} / \mathrm{kg} /$ day: Fig. 2 represents changes in the avoidance response after the repeated administration of penfluridol for 10 days in a daily dose of $2 \mathrm{mg} / \mathrm{kg}$ p.o. The figure was obtained by plotting the means for each 5 cases at 20 min intervals during a $2 \mathrm{hr}$ daily session. On the 7th day of the administration, only the drug was given. On the 6th day after the withdrawal of the administration, $8 \mathrm{mg} / \mathrm{kg}$ p.o. of penfluridol was given, and this effect is also shown in Fig. 2.

On the Ist day of the repeated administration, change in the avoidance response was not observed within $2 \mathrm{hr}$ after the administration. On the 2 nd day, the response was suppressed, thus both the response and avoidance rates were lowered. The suppressive effect was nearly the same after a single administration of $2 \mathrm{mg} / \mathrm{kg}$. On the $3 \mathrm{rd}$ day, the suppressive effect was more enhanced, and on the 4th day and later, a nearly constant suppression was 

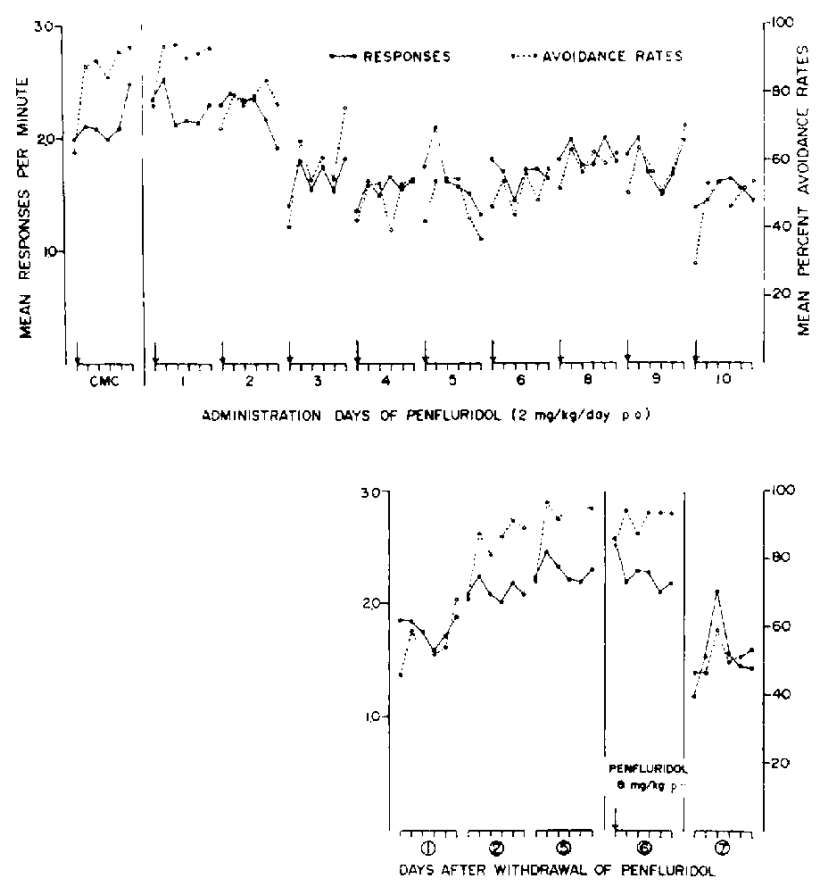

rT T-T The mans, $20 \mathrm{~min}$

Fig. 2. Effects of the repeated administrations of penfluridol $2 \mathrm{mg} / \mathrm{kg} \mathrm{p}, \mathrm{o}$. on the conditioned discriminated avoidance response. The $2 \mathrm{hr}$ daily session is divided into six $20 \mathrm{~min}$ intervals, and mean response and avoidance rates for each interval are plotted.

maintained. At 3-4 days after the withdrawal of the repeated administration, the initial baseline was restored.

On the other hand, the administration of $8 \mathrm{mg} / \mathrm{kg} \mathrm{p.o.} \mathrm{of} \mathrm{penfluridol} \mathrm{on} \mathrm{the} \mathrm{6th} \mathrm{day}$ after the withdrawal of the repeated administration, elicited changes in the response and avoidance rates which were always reproduced after a single administration of the same dose.

$4 \mathrm{mg} / \mathrm{kg} / \mathrm{day}$ : Fig. 3 represents, in the same way as Fig. 2, changes in the avoidance response after the repeated administration of $4 \mathrm{mg} / \mathrm{kg} /$ day p.o. for 10 days. Also the results of oral administrations of 4 and $8 \mathrm{mg} / \mathrm{kg}$ at 8 and 15 days, respectively, after the withdrawal are shown here.

As in the case of $2 \mathrm{mg} / \mathrm{kg}$; day, no change was observed on the 1st day, but on the 2 nd day, a change which was comparable with that after a single administration of $4 \mathrm{mg} / \mathrm{kg}$ appeared. The effect was more enhanced on the $3 \mathrm{rd}$ day, and later nearly a constant level of suppression was maintained. At 3-4 days after withdrawal, the initial baseline was recovered. Changes in the avoidance response elicited by 4 and $8 \mathrm{mg} / \mathrm{kg}$ of penfluridol at the 8 th and 15 th days, respectively, after the withdrawal, did not differ from those after single administrations of the same doses.

$8 \mathrm{mg} / \mathrm{kg} /$ day: Fig. 4 represents, in the same way as Figs. 2 and 3, changes in the avoidance response, elicited by repeated administration of $8 \mathrm{mg} / \mathrm{kg} /$ day p.o. of penfluridol 

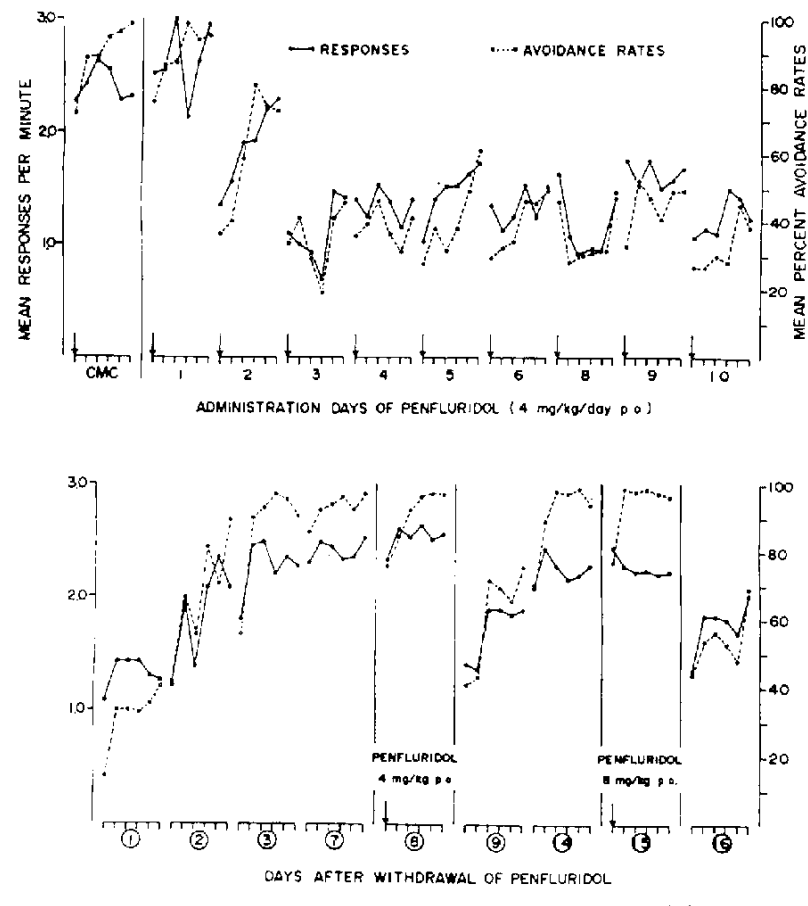

FIG. 3. Effects of the repeated administrations of penfluridol $4 \mathrm{mg} / \mathrm{kg}$ p.o. on the conditioned discriminated avoidance response (expressed in the same way as in Fig. 2).
Fig. 4. Effects of the repeated administrations of penfluridol $8 \mathrm{mg} / \mathrm{kg}$ p.o. on the conditioned discriminated avoidance response (expressed in the same way as in Figs. 2 and 3).
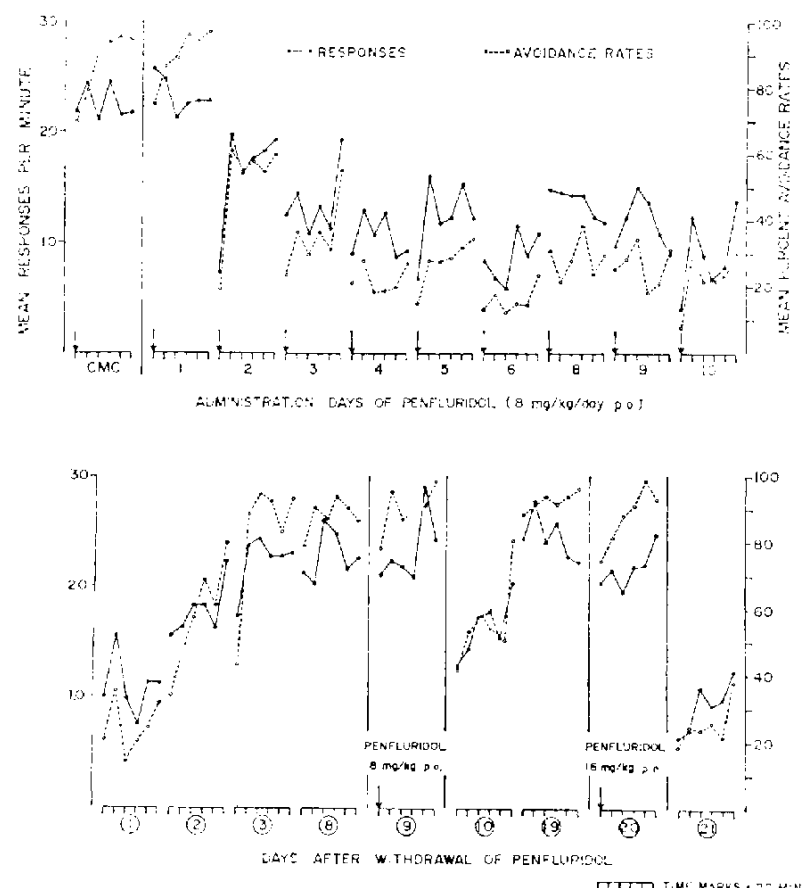
for 10 days. It also shows the results of 8 and $16 \mathrm{mg} / \mathrm{kg}$ given on the 9 th and 20 th days, respectively, after the withdrawal.

As in the cases of administrations of 2 and $4 \mathrm{mg} / \mathrm{kg} /$ day, no change was apparent in the avoidance response on the 1 st day. On the 2 nd day, however, change to nearly the same degree as that after a single administration of the same dose was maintained, and the suppression was progressively enhanced with the repetition of the administration. On the 4th day and later, the suppressive effect remained nearly constant. About 3-4 days time was required after the withdrawal to recover initial levels. Changes in the avoidance response elicited by 8 and $16 \mathrm{mg} / \mathrm{kg}$ p.o. given on the 9 th and 20th days, respectively, after the withdrawal were always reproduced after a single administration of the same doses.

Fig. 5 summarizes the daily changes in the response and avoidance rates, elicited by 2,4 and $8 \mathrm{mg} / \mathrm{kg}$ p.o. of penfluridol daily for 10 consecutive days. The figure was obtained by plotting the means for each $2 \mathrm{hr}$ session on the same coordinate. It also represents the
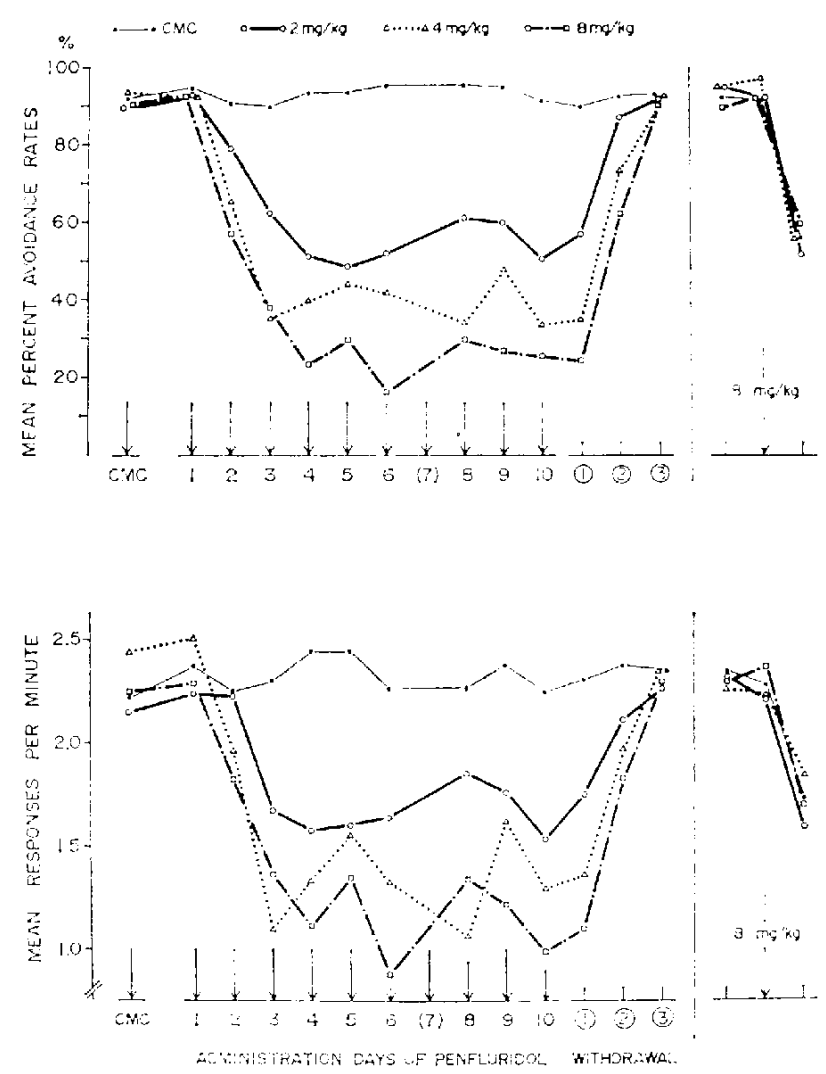

FIG. 5. Temporal changes of mean response and avoidance rates in the conditioned discriminated avoidance performance, elicited by $2-8 \mathrm{mg} / \mathrm{kg}$ p.o. of penfluridol daily for 10 consecutive days. The figure was obtained by plotting the means for each $2 \mathrm{hr}$ session on one same coordinate.

Upper: Avoidance rates. Lower: Response rates. 
result of the control experiment with $\mathrm{CMC}$ alone, as well as the recovery process after the withdrawal and the succeeding changes elicited by the readministrations of $8 \mathrm{mg} / \mathrm{kg}$ p.o. of penfluridol.

CMC alone did not produce any change either in the response or in the avoidance rates, whereas the repeated administration of penfluridol progressively enhanced the changes at any of the three doses until the $3 \mathrm{rd}-4$ th day, when a plateau was attained and maintained during the later medication. Suppression of the response and avoidance rates clearly paralleled the dosage given. On the 2 nd day after the withdrawal, the recovery became evident, and on the 3rd day, the initial level was almost restored, regardless of the dose which had been given. Abstinence symptoms were not confirmed behaviorally during the recovery course.

The readministrations of $8 \mathrm{mg} / \mathrm{kg}$ p.o. of penfluridol at $1-2$ weeks after the discontinuation gave the response and avoidance rates of $1.57-1.77 / \mathrm{min}$ and $52-60 \%$, respectively, which correspond well to $1.73 / \mathrm{min}$ and $55 \%$ seen with the single administration of $8 \mathrm{mg} / \mathrm{kg}$, thus manifesting no effect of the previously given penfluridol or CMC.

\section{Study on accumulation of penfluridol}

The cumulative effect of penfluridol was quantitatively examined by observing changes elicited by single and repeated administrations of $2-16 \mathrm{mg} / \mathrm{kg}$ and $2-8 \mathrm{mg} / \mathrm{kg} / \mathrm{day}$, respectively, in the avoidance response acquired under the conditioned discriminated avoidance schedule.

Fig. 6 compares the dose-effect relations between single and repeated administrations of penfluridol. The former was obtained by calculating the mean response and avoidance rates at 24 and $48 \mathrm{hr}$ after giving 2-16 and $8-16 \mathrm{mg} / \mathrm{kg}$, respectively, and the latter by the means at 4-10 days of administrations of $2-8 \mathrm{mg} / \mathrm{kg} /$ day. At $48 \mathrm{hr}$ after the single administrations of $2-4 \mathrm{mg} / \mathrm{kg}$, no marked effect was manifested.

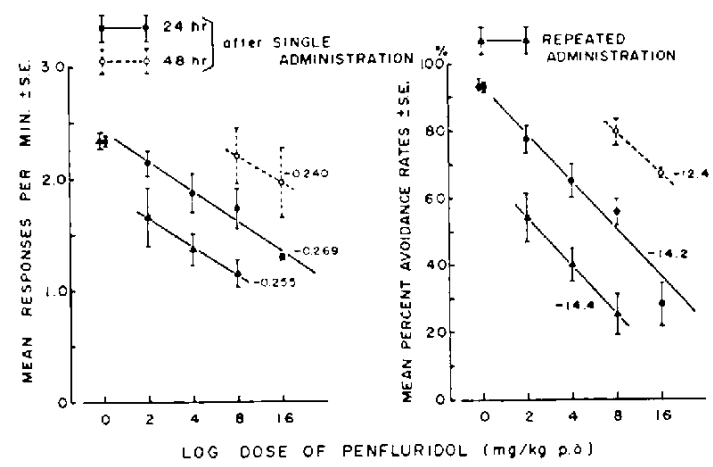

FIG. 6. Dose-effect correlations of single and repeated administrations of penfluridol. The former was obtained at 24 and $48 \mathrm{hr}$ after $2-16 \mathrm{mg} / \mathrm{kg}$ and $8-16 \mathrm{mg} / \mathrm{kg}$, respectively, and the latter by the mean values during 4-10 days of administrations of $2-8 \mathrm{mg} / \mathrm{kg} / \mathrm{day}$. The figures by the straight lines indicate the inclinations.

Left: Response rates. Right: Avoidance rates. Vertical lines indicate standard error. 
When the response or avoidance rate is given on the ordinate, and the logarithmic doses on the abscissa, the dose-effect relations are given as a straight line. The dose-effect curves after $24 \mathrm{hr}$ of single and after repeated administrations were determined by the method of least squares. As for the line after $48 \mathrm{hr}$, two points, giving the measured values were connected. The figure by each line indicates the inclination of the line. The lines are identical in slope, indicating good correspondence between the response and avoidance rates. The response and avoidance rates after $24 \mathrm{hr}$ of single administrations of $2-16 \mathrm{mg} / \mathrm{kg}$ p.o. are given by the following formulas:

Response rate $=2.43-0.269 \log _{2} \mathrm{D}$

Avoidance rate $=93.4-14.2 \log _{2} \mathrm{D}$,

where the response rate gives the numbers of lever-pressing per min, and $\mathrm{D}$ the dose of penfluridol in $\mathrm{mg} / \mathrm{kg}$.

When the mean response and avoidance rates at 4-10 days of the repeated administration are calculated by the above formulas, it can be seen that the suppressive effect of the repeated administration is 3.4-3.8 times as high as that of the single application in terms of the response rate, and 3.4-3.5 times in terms of the avoidance rate. Thus the effect of repetition of one lime daily application was on the average 3.5 times that of the single one. The response and avoidance rates at $48 \mathrm{hr}$ after the single administration as calculated from the two formulas show that the values are $0.21-0.23$ and $0.23-0.25$ times as low as those at $24 \mathrm{hr}$ after the administration, respectively. This means that at $48 \mathrm{hr}$ after dosing, the effect of penfluridol is reduced to about $1 / 4$ of that at $24 \mathrm{hr}$.

\section{DISCUSSION}

In the present experiment with rats, a relatively long time of training was necessary for the establishment of the stable behavioral baseline under the conditioned discriminated avoidance schedule. Once established, however, the baseline was highly stable for a long time, and except for the first 10-20 min after the start of the session, when warm-up effect was present, all animals pressed the lever exactly during the warning period, avoiding the imminent clectric shock at the rate of $90-95 \%$. The daily variation in the response rate was also small.

On the other hand, neuroleptic drugs exert a specific effect on the conditioned avoidance response, showing in this case an evident dose-effect relationship (10). It is moreover considered that the suppressive effect of the drug on the conditioned avoidance response may have a high corrclation with its clinical antipsychotic efficacy $(11,12)$. Thus, the conditioned discriminated avoidance schedule is assumed to be an appropriate method not only for the preclinical assay of antipsychotic effect of neuroleptic drugs, but also for estimation of the cumulative effect, since a stable bchavioral baseline is maintained for a long time.

Penfluridol is a psychotropic derivative of diphenylbutylpiperidine, and the present authors (1) have already examined in detail the effects on various operant behavior. They reported that this agent bclongs to the category of neuroleptic drugs. It was elucidated by 
their experiment that the minimal oral dose for the evident suppression of both Sidman-type and the discriminated avoidance responses, was $2 \mathrm{mg} / \mathrm{kg}$. The effect persisted for $2-3$ days after the administration, though the manifestation was delayed. Clinically it exerted an antipsychotic effect, which also was long lasting (13-16).

The effect of a single administration of penfluridol on the conditioned discriminated avoidance response in the present experiment was consistent with the previous report (1). On the other hand, it was found that the avoidance-suppressing effect of repeated administration was stronger than that of the single application of the same dose. This can be attributed to the cumulative effect for the following three reasons. First, a steady state was attained after 4-time repetitions of the administration, independently of the doses. This result is in agreement with the plateau principle of drug accumulation proposed by Goldstein et al (5). Second, neither physical nor behavioral tolerance (17) developed as readministrations of $8 \mathrm{mg} / \mathrm{kg}$ p.o. 1 or 2 weeks after the withdrawal elicited nearly identical changes as that after a single administration of the same dose, regardless of the previous doses of the repeated administration. Third, the dose-effect curves after repeated administration appeared to be the result of parallel shifting of those after the single administration. Thus, the maximum level of drug accumulation was dependent only on the dose. This is in agreement with the general derivation $(5,6)$ that, when the interval of the administration is fixed, the level can be expressed in constant inultiples of the first dose. Moreover the comparison of the dose-effect relationships between the single and repeated administrations revealed that the effect of the latter was about 3.5 times as high as that of the former. After 4-time repetitions, the absorption, metabolism and excretion of the drug were considered to be brought to a balance, thus presenting a plateau.

Also the dose-effect curves at $48 \mathrm{hr}$ after the single administration seemed to be the result of parallel shifting of those at $24 \mathrm{hr}$. It was thus demonstrated that the effect at $48 \mathrm{hr}$ fell to about $1 / 4$ of that at $24 \mathrm{hr}$. According to a report from the Janssen Laboratory (18), when the intracerebral and plasma radioactives were counted after the oral administration of the tritium-labelled penfluridol $0.16-10.0 \mathrm{mg} / \mathrm{kg}$ to rats, ratio of the activities between 32 and $64 \mathrm{hr}$ after the administration ranges $0.23-0.27$. Such is in fairly good agreement with our results that the reduction of the effect at $48 \mathrm{hr}$ is $1 / 4$ of that at $24 \mathrm{hr}$.

The results of the present experiment have significance not only in the qualitative demonstration of the cumulative effect of repeated administration of penfluridol, but also in predicting the pharmacokinetics of this drug by means of the degree of the suppressive effect on the avoidance response in rats.

\section{REFERENCES}

1) Kuribara, H., Okuizumi, K., Silirota, M. and Tadokoro, S.: Folia pharmacol, japon. 71, 491 (1975) (in Japanese)

2) Gaddum, J.H.: Nature 153, 494 (1944)

3) Shannon, J.H., Earlf, D.P. Jk., Brodie, B.B., Taggart, J.V. and Berliner, R.W.: J. Pharmacol. exp. Ther. 81, 307 (1944)

4) Goldstein, A., Krayer, O., Root, M.A., Acheson, G.H. and Doherty, M.E. I. J. Pharmacol. exp. Ther. 96, 56 (1949) 
5) Goldstein, A., Aronow, L. And Kalman, S.M.: Principles of Drug Action. The Basis of Pharmacology, Harper and Row Publ., New York (1969)

6) Wells, J.A.: Pharmacology in Medicine, Edited by Drill, V.A., p. 12, McGraw-Hill, New York (1958)

7) Hoffman, H.S.: Operant Behavior, Edited by Honta, W.K., p. 499, Appleton-CenturyCrofts, New York (1966)

8) TADOKORO, S.: Folia pharmacol. japon. 68, 536 (1972) (in Japanese)

9) Tadokoro, S. and OGawa, H.: Basic Pharmacol. Ther. 2, 1189 (1974) (in Japanese)

10) Tadokoro, S.: Basic Pharmacol. Ther. 2, 1412 (1974) (in Japanese)

11) COOK, L. ANd Kelleher, R.T.: A. Rev. Pharmacol. 3, 205 (1963)

12) Nakamura, K., Zbinden, G. And Randall, L.O.: Pharmacology of Psychotropic Drugs, Asakura, Tokyo (1971) (in Japanese)

13) Janssen, P.A.J., Niemegeers, C.J.E., Schellekens, K.H.L., Lenaerts, F.M., Verbruggen, F.J., Van Nueten, J.M. and Schaper, W.K.A.: Europ. J. Pharmacol. 11, 139 (1970)

14) Bobon, J., Melon, J., Mormont, C., Dufrasne, M. And Pinchard, A.: Acta psychiat., Belg. 70, $523(1970)$

15) Baro, F., DOM, R. AND VAN LommeL, R.: Seventh Congress of the Collegium Internationale Neuro-Psychopharmacologium, August, Prague, Czechoslovakia (1970)

16) Baro, F., Brugmans, J., Dom, R. and Van Lommel, R.: J. clin. Pharmacol. 10, 330 (1970)

17) Tadokoro, S., Ogawa, H., Ohashi, K., Kanazawa, Y., Konishi, T. and Murata, M.: Japan. J. clin. Pharmacol. 2, 356 (1971) (in Japanese)

18) Janssen Research Products Information Service, Section 11, Biological Research Reports, June (1971) 